\title{
How can Simulation Coaching Improve Emotional Intelligence Skills and Situational Awareness in Child Protection Professionals?
}

\author{
By Mari Salminen-Tuomaala*
}

\begin{abstract}
Emotional intelligence (EI) and situational awareness (SA) are important attributes for child protection professionals. In this qualitative study conducted in Finland, the aim was to explore how simulation-based learning could improve EI and SA of child protection professionals. Based on a learning needs assessment, a simulation-based educational intervention was provided for 36 professionals in 5 private providers of substitute care services for under 18-year-old children. Directly after the intervention, the participants were asked to recount in a short essay how the educational intervention had affected their EI and SA and other professional competence. Inductive content analysis was used to analyze the essays. The analysis revealed that the simulation coaching had been meaningful to the participants from four perspectives, increasing their awareness of their own and others' emotions; making them better prepared to project themselves into another person's position; increasing team intelligence, and as a form of work supervision. The results indicate that simulation coaching can be considered a useful tool for the development of EI, SA and related competencies in child protection professionals. Other professionals, whose work essentially involves close interaction with clients, may also consider the transferability of the findings to their work.
\end{abstract}

Keywords: child protection, emotional intelligence, situational awareness

\section{Introduction}

Emotional intelligence, empathy and situational awareness are considered to be essential attributes for health and social care professionals. These were also among the most important self-assessed learning needs of the child protection professionals, who took part in the simulation coaching programme and qualitative study addressed in this article.

The simulation coaching and study described in this paper were part of a larger research, development and training project carried out in a western region of Finland in 2017-2019. The project aimed at improving the competence of staff working for private providers of health and social care services in the region.

The overall project involved a combination of learning needs assessments, educational interventions and research, carried out with 20 private small or medium-sized companies operating in child protection, geriatric care, mental health services and disability services. In all, 230 health and social care professionals took part in the project, which received support from the European Social Fund.

*Principal Lecturer, School of Health Care and Social Work, Seinäjoki University of Applied Sciences, Finland. 
This sub-study concentrates on an intervention and study carried out with 36 professionals from 5 providers of substitute care services for children. In this study, as in Finnish child protection legislation, the term child refers to anyone under 18. Based on the results of a learning needs assessment, the professionals took part in a simulation-based coaching and an ensuing qualitative study. The research question was:

How can simulation coaching improve emotional intelligence skills and situational awareness in professionals working for private providers of child protection services?

The study methodology was based on the concept and training developed by teachers at two educational institutions in western Finland: Seinäjoki University of Applied Sciences and Sedu Vocational Education Centre. The University is a multidisciplinary institution of higher education with Bachelor and Master-level degree programmes, including degree programmes in nursing, public health nursing, physiotherapy, elderly care and social work. The University has approximately 4,800 full-time students (Seinäjoki University of Applied Sciences 2020). The Vocational Education Centre offers upper secondary-level vocational qualifications in various fields of study for over 5,000 students, including practical (enrolled) nurses and emergency medical technicians (Sedu Vocational Education 2020).

The simulation-based coaching provided in the five companies was based on the participants' self-assessed continuing learning needs. The participants had wished to develop interaction with the children through the development of their emotional intelligence, empathy skills and situational awareness.

In the literature review, the topics of child maltreatment, child protection services and competence required from child protection professionals are addressed first, with special reference to the situation in Finland. This is followed by a discussion of the concepts of emotional intelligence (EI) and situational awareness (SA), considered essential qualities for professionals working with children in need of protection. The latter part of the article presents the methods and findings of the qualitative study conducted with the professionals, starting with a description of the simulation coaching intervention carried out with 36 child protection professionals wishing to improve their EI and SI. The final section of the paper discusses the findings and their implications for practice and education.

\section{Literature Review}

\section{Child Maltreatment}

Maltreatment of children is a worldwide problem. Physical, sexual or emotional abuse, and neglect and exploitation experienced by children (persons aged under 18 years) has been found to have lifelong consequences, manifested in behavioural, physical and mental health problems (WHO 2020, Rantanen and Paavilainen 2018). According to the World Report on Violence and Health (Krug et al. 2002), there are four levels of risk factors that make children vulnerable to 
various types of violence: individual, close relationship, community and societylevel. In addition to influence within a single level, the interaction between these factors can place children at risk.

In Finnish literature on child maltreatment, the accumulation of risks in the family, as well as the transfer of risks from one generation to another have been discussed by Paavilainen and Flinck (2013, 2015, Flinck and Paavilainen 2016). They have described the intergenerational transmission of social disadvantage and social exclusion often connected with multiple problems like long-term unemployment, poor health, intoxicant abuse and domestic violence. The investigators also note, however, that although there is no denying that social disadvantage and the accumulation of multiple problems is associated child maltreatment, the cause-effect relationship is more complex than what one might expect. Some families are more vulnerable, some respond to adversity with more resilience (Flinck and Paavilainen 2016).

Paavilainen and Flinck (2013) have also developed a clinical nursing guideline, based on a review of 77 research articles and review and discussion papers, to help nurses to identify and intervene in child maltreatment. The investigators list risk factors which may manifest themselves in the child, the parents or the whole family, and discuss physical and other signs caused by maltreatment. They also point out that home and health clinic visits provide a good opportunity to discuss child-rearing practices, family relationship and potential violence present in family life (Paavilainen and Flinck 2013).

\section{Child Protection Services}

$\underline{\text { Goal }}$

In 2019, almost 20,000 children were placed in out-of-home care in Finland (population 5.5 million). In addition, over 50,000 home-living clients received support and various child protection services. These services, where the focus is very much on prevention and early support, are commonly referred to as child welfare services in English translations of Finnish texts (Finnish Institute for Health and Welfare 2020a).

According to the Child Welfare Act (2007), in the assessment of child protection needs and implementation of services, the best interests of the child should be a primary consideration. The quality recommendation for child welfare of the Finnish Ministry of Social Affairs and Health (2019) stresses the importance of recognizing children's distress and providing help, irrespective of where they live or what services they already receive. Appropriate measures and solutions should be sought to safeguard the following for the child:

"1) balanced development and wellbeing, and close and continuing human relationships; 2) the opportunity to be given understanding and affection, as well as supervision and care that accord with the child's age and level of development; 3) an education consistent with the child's abilities and wishes; 4) a safe environment in which to grow up, and physical and emotional freedom; 5) a sense of responsibility in becoming independent and growing up; 6) the opportunity to become involved in 
matters affecting the child and to influence them; and 7) the need to take account of the child's linguistic, cultural and religious background" (Child Welfare Act 2007).

Besides promoting the child's development and wellbeing, the child welfare services are obliged to support parents, other custodians and persons responsible for child care and upbringing. Prevention and early intervention are included in the concept of child welfare, and governed by law (Child Welfare Act 2007). The work of child welfare professionals must be based on the fairness (rights enshrined in the Convention on the Rights of the Child); openness and reliability (transparent knowledge, predictable and justified practices); safety of the child, and the principle of proportionality. This means that official actions should meet the child's needs at the lowest level of intervention (Finnish Ministry of Social Affairs and Health 2019).

\section{Substitute Care for Children in Finland}

Municipalities, which are urban, semi-urban or rural areas with a population range of 690 to over 650,000 , are responsible for organizing social and health services. Finland has currently 310 municipalities (Association of Finnish Municipalities 2020). In Finnish child welfare, supporting children in their homes must be given precedence over substitute care. Even when substitute care is provided, the aim of reuniting the family should be taken into account as far as possible (Child Welfare Act 2007).

The municipal bodies responsible for social services have a duty to take a child into care and provide substitute care if the child's health or development is seriously endangered due to lack of care or other circumstantial factors, or if the child has been found to abuse intoxicants, commit illegal acts or engage in other comparable behaviour, which endangers his or her health or development. After a child has been taken into care, the municipal body responsible for social services decides about the child's placement, care and other necessary services, seeking cooperation with the child's parent or guardian (Child Welfare Act 2007).

In Finland, children taken into care can be placed in family care, professional foster homes or institutions. Family care is the primary form of substitute care. The foster parents, also called family carers, provide 24-hour care in their own homes. The aim of family care is to provide a safe environment and close relationships for the child, and to promote the child's social development and sense of security (Family Care Act 2015). Institutional care in children's homes is only arranged if the child's foster care cannot be arranged in home care (Child Welfare Act 2007). The third form of substitute care is provided by professional foster homes, which resemble family care, but in which the foster parents and often staff members have a social or health care qualification. The entrepreneur or manager responsible for a professional foster home must hold a Bachelor's of social work degree or equivalent. These homes can accommodate children with special needs (Finnish Institute for Health and Welfare 2019b). Most of the participants in this study represented professional foster homes. 


\section{Competence Required in Substitute Care for Children}

Foster parents and professionals working within child protection are accountable for their work to the child, the child's family, the organization where they work, and society. Important attributes required in this work involve, but are not restricted to, client knowledge, interaction competence and personal and professional development.

First, client knowledge refers to a good understanding of child development, risk and protective factors, trauma and psychological disorders. Those working in child protection must also know how to encounter diversity and different cultures (Rantanen and Paavilainen 2018).

Second, a wide range of interaction skills are necessary. Respect, humanity and empathy are required when working with children typically affected by trauma, neuropsychiatric disorders or difficulty interacting with others (Finnish Ministry of Social Affairs and Health 2019b). It can be argued that good interactions skills are based on emotional intelligence and situational awareness. The child is entitled to age-appropriate information, and the child's opinion must be listened to and taken into consideration (Child Welfare Act 2007). In addition, the foster parents or professionals need to allocate sufficient time for transparent, constructive interaction with the child's family, and for collaboration with a number of health and social care authorities and professionals. Support from other multiprofessional collaboration, for example through crisis intervention, therapy and other social and health care services is required especially when dealing with the consequences of domestic violence, child abuse and other traumatic events (Finnish Institute for Health and Welfare 2019b, Finnish Ministry of Social Affairs and Health 2019).

Third, personal and professional development here refers to opportunities for continuous learning and reflection on one's and the team's work (Rantanen and Paavilainen 2018). The Finnish Ministry of Social Affairs and Health (2019) stresses the importance of providing workers an opportunity to stop to evaluate their contribution, to examine their experiences, challenge existing beliefs and learn new practices and ways of thinking. Critical self-evaluation, reflection and continuous learning should also take place at the level of teams and organizations. Collective professional knowledge constructed within teams shapes the thinking of individual workers, at best improving the work quality, at worst leading to dead routines. Reflective practice can make the work more meaningful and it is essential for the renewal of work and consolidation of professional competence (Finnish Ministry of Social Affairs and Health 2019).

\section{Emotional Intelligence and Situational Awareness}

The need to consciously develop emotional intelligence (EI) and situational awareness (SA) is increasingly recognized in health and social care research, practice and education (Freshwater and Stickley 2004, Stamer 2017, Karimi et al. 2020, Salminen-Tuomaala 2020). EI and SA were among important self-assessed learning needs of the child protection professionals, who took part in the simulation coaching programme and qualitative study described in this article. EI 
and AI can also be considered relevant from the perspective of the three attributes required in substitute care for children, discussed above: client knowledge; interaction competence, and personal and professional development. Emotional intelligence is required in the establishment of client relationships, and in seeking to understand client's mood, experiences and emotions. EI, which is a combination of emotional and cognitive components (Salovey et al. 2004), is also an important component in problem-solving and decision-making (Akerjordet and Severinsson 2004) and in recognizing and understanding clients' individual needs (Kooker et al. 2007).

Emotional intelligence has been conceptualized as "the ability to recognize and manage one's emotions, to recognize other people's emotions and to use this information to guide one's thinking and action" (Salovey et al. 2004). According to this definition, EI is rather seen as an ability or a form of intelligence than a personality trait. Salovey et al. (2004) have proposed that EI can develop through four levels, from the ability to accurately perceive emotions, to conscious, reflective management or regulation of emotions. Another definition, proposed by Mikolajczak (2009), combines the conflicting perspectives of ability EI and trait EI in a Three-Level Model of EI: knowledge- abilities -dispositions. The first level refers to a person's knowledge about emotions and emotional skills, the second to the ability to apply knowledge in emotional situations, and the third (trait-level) to the tendency to use emotional skills/competences in daily life.

A systematic review of 46 EI intervention studies (Kotsou et al. 2018), conducted with various adult groups including medical and nursing professionals, provided some support for the efficacy of the interventions. The findings from the review suggested that various aspects of EI competencies could be improved in a way that benefits psychological health. Even a brief intervention can result in positive changes in psychological well-being, self-reported health, social relationships and employability (Nelis et al. 2011). Investigators stress the need for more research in order to confirm that EI interventions improve work and academic performance (Kotsou et al. 2018).

To move on to the other important concept in this study, situational awareness (SA) has been defined as the "perception of the elements in the environment in a volume of time and space, the comprehension of their meaning and the projection of their status in the near future" (Endsley 1995a). In other words, elements are perceived, their meaning understood in relation to the situation at hand, and an estimate or forecast of what will happen next is conducted. SA is essential for safe practice in high risk and stress situations (Lowe et al. 2016). It is dynamic, ongoing and iterative in nature, with new information received by professionals informing their new actions (Busby and Witucki-Brown 2011).

Situational awareness does not only refer to an attribute of individual professionals; it is considered to occur at team and organizational levels as well. The concept Team Situational Awareness or TSA is used for the cognitive processes and behaviours of team members acquiring and sharing information and knowledge about a situation (Endsley 1995b). 
In medical and nursing sciences, early research on situational awareness focused on medical settings using measurement frameworks from aviation industry. Situational awareness is regarded as an important non-technical skill that helps to ensure patient/client safety. It has been proposed, for example, that SA education should be included in nursing curricula (Stubbings et al. 2012). The use of high fidelity simulation has been recommended for the training of situational awareness and teamwork skills (Eddy et al. 2016, O'Meara et al. 2014). The recognition that situational awareness is a precursor of, or a primary basis for clinical judgment and decision-making, has led to an increasing body of healthcare literature (Stubbings et al. 2012, Endsley and Jones 2012). Clinical judgment has been defined as "interpretation or conclusion about a patient's needs, concerns, or health problems and/or the decision to take action (or not), use or modify standard approaches, or improvise new ones as deemed appropriate by the patient's response" (Tanner 2006).

\section{Simulation Pedagogy}

In adult education, immersing the learner in an event that simulates the real world is considered to be an effective approach. Simulations, preceded by preparation and followed by feedback and debriefing of the experience, have been found to enhance active learning and the likelihood that the learners will be able to apply the knowledge and skills later, when confronted with similar situations in "real life" (e.g., Bethune et al. 2011, Banerjee et al. 2016).

One of the definitions for simulation is "artificial representation of a phenomenon or activity that allows participants to experience a realistic situation without real-world risks" (Larew et al. 2006). Well-planned simulation-based learning allows an opportunity to reflect on the learning experience and real-life practice in a safe, motivational learner-centred environment, supported by expert educators (Kneebone 2005). The methods used and the levels of difficulty can and should vary according to the context and learning objectives (e.g., Doolen et al. 2014, Williams et al. 2017).

Simulation-based learning has a long history in healthcare education, and it has been proposed that social work education should learn from medical and health science education to develop simulation-based teaching and learning (Dodds et al. 2018). A recent scoping review of 52 articles showed an increase in simulation-based learning in social work education. The review also revealed that facilitators reported in the articles to simulation-based learning were similar to best practice standards in medicine and nursing: immediate feedback, reflection, adequate preparing, clear learning objectives and supportive learning environment. In both social work and healthcare professions, simulations can be useful tools for learning holistic competence (Kourgiantakis et al. 2019), specialized competencies, and for learning to deal with infrequent clinical situations or safety risks (Brown 2008, Kourgiantakis et al. 2019).

Health and social work professions share many competencies that can be practised using simulation-based learning. These include, but are certainly not limited to, emotional intelligence, situational awareness, therapeutic 
communication, crisis management and clinical judgment (Brown 2008, Decker et al. 2008, Salminen-Tuomaala 2020). Emotional intelligence skills can be achieved through simulation-based learning, because it provides an opportunity for learners to confront a dilemma and explore their emotional and intellectual reactions without clinical responsibility. In other words, it could be argued that fostering self-awareness is an essential component in simulation-based learning (Brown 2008).

\section{The Study}

Here it is described the educational intervention and study carried out with 36 professionals from 5 providers of substitute care services for children in Finland. The coaching applied in the simulation provided in the five companies was based on the method developed by Seinäjoki University of Applied Sciences and Sedu Vocational Education according to the self-assessed continuous learning needs of the participants. The purpose of the research was to explore how simulation coaching could improve emotional intelligence skills and situational awareness in professionals working for private providers of child protection services.

\section{Participants}

The study was conducted in western Finland. The 36 participants, 18 women and 18 men, represented private providers of child protection services. They worked in four professional foster homes and one children's home, located across four municipalities. All the participants had completed a Bachelor's degree or equivalent in nursing $(n=30)$ or social services $(n=6)$. They were mainly involved in guiding and helping the children, supporting their health, development and education. In three companies, the entrepreneurs took part in the simulation sessions. Their duties included administrative tasks in addition to guidance and education. The length of the participants' work experience varied between 2 and 20 years.

\section{The Simulation Coaching Concept and Intervention}

Based on the participants' wishes and on the assessment of learning needs, two teachers (called coaches), usually one representing health care and the other social work, planned and implemented the simulated scenarios as team work. A non-authoritative mentoring and coaching approach was applied. The concept very much relied on the ideas of learning from peers and on multi-professional collaboration between social and healthcare. Special attention was paid to participants' background. Their earlier work experience was appreciated and used as a foundation for the learning. The coaches made an effort to create an open and warm atmosphere. Ethical principles for the sessions were also discussed during the preparation stage; it was agreed that sensitive issues brought up during the 
sessions were confidential and should not be taken up after the sessions, unless specifically agreed with all participants.

The coaching was mainly implemented in the participants' own facilities, which can be thought to facilitate transfer to the workplace context and allowed several persons from the same workplace to participate simultaneously. The coaches limited the number of participants to 16 to ensure that everybody had the time and space to become intensively involved. Ideally, 10 participants would be a suitable group size. All simulation sessions started with preparation and ended with debriefing; that is feedback discussions and shared reflection (SalminenTuomaala 2019, Salminen-Tuomaala et al. 2020).

The simulation sessions took place mostly in multi-professional groups. One or two days were arranged in each company. One day involved no more than three scenarios, because the experience of role-playing was often considered intense or demanding. The scenarios, led by the two coaches or teachers specialized in the topic, revolved around various interaction situations between the children and personnel. Before acting out the scenarios, definitions and models related to emotional intelligence and situational awareness were introduced. The participants also discussed factors that had shaped their emotional intelligence and personal development, and factors that had burdened them and caused stress at work.

The length of individual scenarios was approximately 20 minutes. The scenarios were always followed by 60 minutes provided for reflection and discussion. Before the scenarios, the participants were briefed about an initial situation involving carefully constructed challenging roles, and asked to respond to the situation as it evolved. One of the coaches simulated the role of the child or teenager, two participants acted out the scenario, and the other participants observed the situation carefully. During the debriefing session, the participants discussed their thoughts, emotions and ways of developing interaction, emotional intelligence, situational awareness and presence.

To give a few examples of the scenarios conducted: In one scenario, a teenager, whose role was played by the coach, had smuggled drugs into her room and now exhibited restless and aggressive behaviour. Two professionals were trying to resolve the incident by talking to the teenager. The rest of the participants were asked to observe the situation and especially to concentrate on issues related to emotional intelligence and situational awareness. Another scenario portrayed a child, diagnosed with attention deficit hyperactivity disorder that was swearing and throwing books on the floor and against the walls. Two staff members were working together in order to help him calm down. In yet another example, a girl acted out her frustration and aggression by kicking and screaming. The pair of professionals reacted by expressing understanding and setting limits on the uncontrolled behaviour.

\section{Data Collection}

Emotional intelligence and situational awareness may be considered elusive concepts and difficult to operationalise. Because of this, and since there is little previous research on the development of EI and SA through simulation in child 
protection services, it was decided to use a qualitative research design and an interpretive paradigm to explore the first-hand experiences of the participants (Puusa and Juuti 2020).

Before taking part in the study, the participants had been involved in three stages of simulation coaching: discussion on relevant concepts as preparation, the actual scenarios and debriefing; that is discussion, feedback and reflection on the actions and processes involved in the scenarios. Directly after the last debriefing discussion, voluntary participants were asked to write down their thoughts in a short essay about how they had experienced the simulation scenarios from the perspective of their professional competence, emotional intelligence and situational awareness.

\section{Data Analysis}

Inductive content analysis was used to analyze the essays. Based on the rich body of material (48 transcribed pages using font 12), the aim was to capture, interpret and understand meanings attached by participants to the simulation coaching situation. The data was first read and re-read several times, and some preliminary observations were noted (Puusa and Juuti 2020). The meaning units or significant statements that appeared to relate to the research question and provided an understanding of how the participants experienced the phenomenon were picked out, written in Word files and rewritten as reduced expressions. An effort was made to still retain the original meaning of the text. The reduced expressions were grouped into categories according to content. These categories were grouped under new, higher order headings and, as the last step, combined into main categories. During this process, the investigator returned to the original data multiple times to strengthen the analysis.

\section{Ethics, Rigour and Limitations}

The ethical guidelines of the Finnish National Board on Research Integrity TENK (2012) were observed throughout the research process. The topic was selected because there is little previous knowledge of the development of emotional intelligence and situational awareness through simulation from the perspective of child protection professionals. Participation was voluntary and based on informed consent. Permission to use the data was obtained from all the child protection companies involved in the educational intervention. Only the investigator used the material and it was destroyed after the analysis. The essays were written anonymously. The data provided by the participants cannot be traced back to them (Kuula 2006).

The detailed descriptions in this report can help readers assess the transferability of the findings. In other words, the readers can better decide if the findings are applicable to contexts relevant to them. The carefully conducted descriptions of the research process, participants and setting, combined with good scientific practice, can also help readers assess the credibility and confirmability of the findings, or judge if the results could be corroborated by other investigators. 
The confirmability may have been affected by the fact that the investigator worked alone. It is also acknowledged that her previous experience of nursing and simulation teaching may have influenced the interpretation in two ways; in one hand, the previous knowledge and experience may have facilitated the work, on the other hand, it may have resulted in bias or preconceived preferences or inclinations (Polit and Beck 2012).

The study was conducted in a limited, relatively homogenous geographical area with a population of 200,000. Despite this and the limited number of participants (36), the study offers contributions and insight into the development of emotional intelligence skills and situational awareness through simulation (Cf. Puusa and Juuti 2020). The findings can be of interest to other providers of child protection services in Finland and possibly other countries, and potentially to service providers, whose clients suffer from mental health problems, abuse and traumatic experiences. Nurse and social work educators, providers of continuing education and anyone interested in the development of emotional intelligence and situational awareness through simulation may also consider the transferability of the findings to their work.

\section{Results}

The analysis revealed that the simulation coaching had been meaningful to the participants from at least the following four perspectives, expressed in the main categories Awareness of emotions; projecting oneself into another person's position; Team intelligence, and Supervision of work.

\section{Awareness of Emotions}

According to the respondents, one of the essential outcomes in simulation coaching was learning to recognize and name one's emotions. The coaching was found to increase self-knowledge and helped participants become better aware of their mind-set. They had difficulty admitting that many of their emotions were not positive. On the other hand, they pointed out that negative emotions involved important information about the situation, encouraging reflection on how to respond, and why. The need to bring "self-compassion" and "accepting presence" into the demanding work in child protection was also recognized. The participants indicated that empathy towards oneself was a prerequisite for finding the resources to put oneself in the client's position. However, naming one's emotions and telling about them to the other professionals was considered demanding and made the participants feel vulnerable. They also felt that they had discovered what they called "mirrors" for their thoughts in other people.

In addition to becoming aware of one's own emotions, awareness of other group members' emotions was considered important for building up effective team work and for improving the collective atmosphere. The participants reported having been surprised at learning how many different emotions had been evoked by the scenarios, depending on the participant roles and the professionals' earlier 
experiences. They also found that other people's emotions could be contagious, and reflected on their own role in the group from this perspective. Becoming aware of other workers' negative emotions being caused by stress or various worries or concerns, was mentioned as essential for understanding the working atmosphere and team situations. The participants pointed out that stress and exhaustion could undermine concentration and situational awareness. Especially Scenario 3, originally planned with the regulation of emotions and awareness of others' emotions in mind, was found useful.

\section{Projecting Oneself into Another Person's Position}

Secondly, simulation coaching was found to increase empathy skills, putting oneself into another person's position. According to the participants, "lack of genuine encounters" was one of the key challenges in child protection and foster care. The participants reported having become aware of too many "superficial encounters" that were "lacking in humanity". The simulated scenarios sparked reflection on how too shallow encounters with the children or their parents could lead to feelings of insecurity in the clients, acted out as challenging behaviour. One of the respondents described such behaviour as "loud shouting and attentionseeking", another participant mentioned children avoiding contact and seeking isolation. A third respondent described adults (the children's parents) sometimes seeking to present themselves as "superhuman". The recognition of the perceived lack of genuine contact made the participants ponder how to establish a good contact and dialogue with clients.

According to the participants, the simulated scenarios reminded them of how important it was to project oneself into the client's position. "Accepting presence", concentrating more carefully and expressing interest in what the clients were saying verbally or non-verbally were mentioned as a good starting point for contact. The participants also wrote that "situational sensitivity" and "emotional literacy", or ability to understand other people's emotions and interaction, were required. They felt that for example scenario 1, could help them better understand other people's perspectives and opinions, and place themselves in the client's position. According to the participants, simulation sessions should be repeated from time to time to remind them of the importance of genuine empathy and listening, often forgotten or lost during the daily routines. The participants said that the simulation coaching helped them improve their conversational, listening and feedback skills and increased their courage in expressing their opinions. They had, for example, started to look for new ways to provide encouraging feedback to their clients.

\section{Team Intelligence}

One of the outcomes in this simulation coaching intervention was the participants' experience of increase in what they called "team intelligence" and greater sense of togetherness. According to the respondents, the intervention had made them realize how besides their explicit individual knowledge, their 
workplace was home to a great deal of knowledge owned by other people, including "tacit (silent) knowledge". Acting out the scenarios and the feedback discussions had made the participants aware of how important it was to bring together all competence in the workplace and to make better use of the tacit knowledge in order to reach the common goals. The simulation sessions had inspired them to look for ways to use team intelligence in the daily life at the workplace. In addition, the respondents felt that the simulation coaching had increased tolerance, the feeling of security and open interaction between the professionals.

All these changes or the building up of team intelligence by sharing of knowledge were considered to encourage creativity and flexibility at the workplace. It was recognized that making better use of the professionals' different work experience and competencies would ultimately benefit the whole personnel and company.

\section{Supervision of Work}

Last, the participants felt that the simulation coaching, especially the debriefing sessions, could be regarded as a form of work supervision. The participants welcomed the opportunity to commonly reflect on the challenges encountered in daily interaction with the clients. The debriefing sessions were experienced as a chance to engage in open dialogue on topics that were usually not discussed in everyday life at the workplace. According to the participants, simulation coaching was a method that allowed them to evaluate their work and development needs, and to determine if their aims or objectives defined for the work had been achieved. The coaching made it possible to share and interpret experiences and emotions related to one's role and expertise, to the work community and to the content of their work in a safe atmosphere. The participants also pointed out that the feedback sessions had reduced their anxiety and helped them cope better at work.

\section{Discussion}

This qualitative study was conducted in Finland with 36 professionals from 5 private providers of substitute care services for children. In a learning needs assessment, the most important self-assessed learning needs listed by the professionals had involved the development of emotional intelligence and situational awareness. EI and SA are also mentioned as important attributes for child protection professionals in the National quality recommendation for child welfare (Finnish Ministry of Social Affairs and Health 2019). Emotional intelligence and situational awareness, which include both cognitive and emotional components (Salovey et al. 2004), are most probably best learnt through reflection combined with experiential methods, such as simulation and contextualized learning. For this study, a simulation-based educational intervention, based on a non-authoritative, peer-supported mentoring and coaching approach, was provided 
for the participants of this study to increase their EI and SA. Directly after the intervention, the participants were asked to recount in a short essay how the educational intervention had affected their EI and SA and other professional competence.

The results of this study suggest that simulation-based coaching can be an effective and meaningful method for learning emotional intelligence, situational awareness and teamwork skills. The participants reported increased awareness of their own and other people's emotions; better ability to project themselves into the client's position, and increased team intelligence. They also pointed out that simulation coaching appeared to be useful as a form of work supervision.

According to the participants, the acting out and observation of simulated scenarios combined with shared reflection increased their self-knowledge. Recognition and acceptance of one's own and others' emotions, even negative ones, made the participants better aware of their need for empathy towards themselves as a prerequisite for empathy towards clients. It would seem, based on the results, that the simulation sessions made the participants better aware of their own role and responsibility for the regulation of emotions and success of client and teamwork in the work community. They realized, for example, that daily client encounters could easily become too routinised and unfeeling. The participants described a need to stop and concentrate on better listening and interpretation of verbal and nonverbal cues in clients, and to give them more encouraging feedback. The simulation sessions seem to have not only increased their awareness of these issues, but also improved their interaction skills.

The participants used the terms genuine and accepting presence to describe the desired attributes of client encounters. In Finland, the concept of genuine encounters has been discussed by Kallio (2017), who states that to engage in a genuine encounter with a child, one needs to find the courage to walk alongside the child as a human and incomplete person, but still offer safety and compassion. This approach is based on the understanding that in their incompleteness, emotions, needs and wishes, people resemble each other. The need for contact and the need to be seen and accepted are shared by all humans (Kallio 2017). These needs are pronounced in children who use child protection services.

The participants in this study also used the term increased team intelligence when they described the outcomes of the simulation coaching. The term came from them; it was not among the topics discussed during the preparation phase. The participants talked about sharing of knowledge and sense of togetherness in this context. In literature, the concept of team or collective intelligence has been used in different fields, including psychology, education and business. An attempt has also been made to conceptualise collective intelligence specifically for primary healthcare (Jean et al. 2019). In this framework, what is called a collective dimension includes the components sharing, co-constructing (of knowledge) and constructive conflict of crisis solving, whereas an intelligence-learning dimension involves the components mutual learning, reflective observation, active experimentation and boundary crossing (Jean et al. 2019).

To cite Finnish literature, Hiila et al. (2019) argue that team intelligence and collective situational awareness are the result of collaborative action and potential 
of individual team members, fostered by self-knowledge; shared team direction; tolerant atmosphere; permission to act and responsibility for action, and enriching (encouraging) interaction. Both descriptions, those of Jean et al. (2019) and Hiila et al. (2019), seem to resemble many of the elements described by the study participants as a result of the simulation coaching. These elements involve, for example, increased self-knowledge and becoming aware of the importance of reflection, tolerance/acceptance and encouraging feedback in the work community. According to Hiila et al. (2019), in the increasingly digitalized world, the development of team intelligence and human interaction becomes all the more important (Hiila et al. 2019). The need to provide opportunities for critical selfevaluation, reflection and continuous learning at the team and organization level has also been recognized in the Quality recommendation for child welfare, issued the Finnish Ministry of Social Affairs and Health. Collective professional knowledge constructed within teams and reflective practice can improve the work quality and make the work more meaningful to the professionals (Finnish Ministry of Social Affairs and Health 2019).

Last, the participants of this study found simulation coaching a form of work supervision, which allowed them take time to look at their daily routines from a new perspective and to share their thoughts and emotions in a safe atmosphere. They also had an opportunity to reflect on their professional competence, motives and attitudes. The participants wished that simulation sessions should be repeated from time to time.

All in all, it seems that simulation coaching can be considered a useful and meaningful tool for the development of emotional intelligence, situational awareness and related competencies. The first two categories of findings, awareness of one's own and other's emotions, and the ability to project oneself into another person's position, might primarily be considered as typical features of emotional intelligence. The third category, team intelligence, can perhaps be connected to both emotional intelligence and situational awareness, and the fourth category, simulation coaching as supervision of work, could be seen as a tool to enhance both EI and SA. This is said knowing that there is most probably a complex association between the two concepts, EI and SA.

The findings of this study can be of interest to child protection professionals in Finland and possibly other countries, and potentially to service providers, whose clients have been affected by mental health problems and traumatic experiences. In the context of child protection services, future simulated scenarios could also be constructed around the staff's interaction with the child's parents and significant others. Early childhood educators and staff of primary and secondary schools may also consider the transferability of the findings to their work. The potential differences between women and men's experiences of learning EI skills through simulation-based coaching could be a potential new research topic. 


\section{Conclusions}

The results of this study indicate that simulation coaching can be considered a useful and meaningful tool for the development of emotional intelligence, situational awareness and related competencies in child protection professionals. The coaching can help participants become aware of the risk of becoming routinised and unfeeling, and remind them of the importance of self-empathy, listening and genuine and accepting presence in the daily client encounters. The coaching also provides an opportunity for individual and collective reflection and for the development of professional competence. Reflection, which must always be included in simulation-based education, can be claimed to be an essential element in the process of developing such non-technical skills as EI and SA. In addition to the providers of child protection services, many other professionals, whose work essentially involves close interaction with clients, may consider the transferability of the findings to their work.

\section{References}

Akerjordet K, Severisson E (2007) Emotional intelligence: a review of the literature with specific focus on empirical and epistemological perspectives. Journal of Clinical Nursing 16(8): 1405-1416.

Association of Finnish Municipalities (2020) Tilastot ja julkaisut. (Statistics and publications). Retrieved from: https://www.kuntaliitto.fi/tilastot-ja-julkaisut/kaupun kien-ja-kuntien-lukumaarat-ja-vaestotiedot. [Accessed 23 July 2020]

Banerjee A, Slagle JM, Mercaldo ND, Booker R, Miller A, France DJ et al. (2016) A simulation-based curriculum to introduce key teamwork principles to entering medical students. BMC Medical Education 16(1): 295.

Bethune R, Sasirekha G, Sahu A, Cawthorn S, Pullyblank A (2011) Use of briefings and debriefings as a tool in improving team work, efficiency, and communication in the operating theatre. Postgraduate Medical Journal 87(1027): 331-334.

Brown J (2008) Applications of simulation technology in psychiatric mental health nursing education. Journal of Psychiatric and Mental Health Nursing 15(8): 638644.

Busby S, Witucki-Brown J (2011) Theory development for situational awareness in multicasualty incidents. Journal of Emergency Nursing 37(5): 444-452.

Child Welfare Act (2007) Finlex. Retrieved from: https://finlex.fi/en/laki/kaannokset/20 07/20070417. [Accessed 23 July 2020]

Decker S, Sportsman S, Puetz L, Billings L (2008) The evolution of simulation and its contribution to competency. Journal of Continuing Education in Nursing 39(2): 7480.

Dodds C, Heslop P, Meredith C (2018) Using simulation-based education to help social work students prepare for practice. Social Work Education 37(4): 1-6. DOI: 10.10 80/02615479.2018.1433158

Doolen J, Giddings M, Johnson M, Guizado de Nathan G, Badia LO (2014) An evaluation of mental health simulation with standardized patients. International Journal of Nursing Education Scholarship 11(1): 55-62. 
Eddy K, Jordan Z, Stephenson, M (2016) Health professionals' experience of teamwork education in acute hospital settings. A systematic review of qualitative literature. JBI Database of Systematic Reviews and Implementation Reports 14(4): 96-137.

Endsley MR (1995a) Measurement of situation awareness in dynamic systems. The Journal of the Human Factors and Ergonomics Society 37(1): 65-84.

Endsley M R (1995b) Toward a theory of situation awareness in dynamic systems. The Journal of the Human Factors and Ergonomics Society 37(1): 32-64.

Endsley MR, Jones DG (2012) Designing for situation awareness: an approach to human-centered design. $2^{\text {nd }}$ Edition. Taylor \& Francis.

Family Care Act (2015) Finlex. Retrieved from: https://www.finlex.fi/fi/laki/kaannokset/ 2002/en20020504_20120000.pdf. [Accessed 23 July 2020]

Finnish Institute for Health and Welfare (2019a) Lastensuojelun tilastoa 2019. (Child protection statistics 2019). Retrieved from: https://bit.ly/394FysO. [Accessed 23 July 2020]

Finnish Institute for Health and Welfare (2019b) Lastensuojelun käsikirja. (Handbook for child protection). Retrieved from: https://thl.fi/fi/web/lastensuojelun-kasikirja. [Accessed 23 July 2020]

Finnish Ministry of Social Affairs and Health (2019) Lastensuojelun laatusuositus. (Quality recommendation for child welfare). Helsinki: Sosiaali- ja terveysministeriö.

Finnish National Board on Research Integrity - TENK (2012) Responsible conduct of research and procedures for handling allegations of misconduct in Finland 2012. Retrieved from: https://tenk.fi/en/research-misconduct/responsible-conduct-researchrcr. [Accessed 23 July 2020]

Flinck A, Paavilainen E (2016) Ylisukupolvisen lasten kaltoinkohtelun ehkäiseminen lasten ja perheiden palvelujen haasteena. (From talk to action! The prevention of intergenerational deprivation in social and child welfare services). In K Nousiainen, P Petrelius, L Yliruka (eds.), Puheista tekoihin! Ylisukupolvisten ongelmien ehkäiseminen lastensuojelussa, perhe - ja sosiaalipalveluissa, 92-102. Työpaperi. Finnish Institute for Health and Welfare.

Freshwater D, Stickley T (2004) The heart of the art: emotional intelligence in nurse education. Nursing Inquiry 11(2): 91-98.

Hiila I, Tukiainen M, Hakola I (2019) Tiimiäly, opas muuttuvaan työelämä̈̈n. (Team intelligence, guidebook for the changing world of work). Otavan Kirjapaino Oy.

Jean E, Perroux M, Pepin J, Duhoux A (2019) How to measure the collective intelligence of primary healthcare teams? Learning Health Systems 4(3): e10213.

Kallio M (2017) Inhimillisiä kohtaamisia. (Compassionate encounters). WSOY.

Karimi L, Leggat SG, Bartram T, Rada J (2020) The effects of emotional intelligence training on the job performance of Australian aged care workers. Health Care Management Review 45(1): 41-51.

Kneebone R (2005) Evaluating clinical simulations for learning procedural skills: a theory-based approach. Academic Medicine 80(6): 549-553.

Kooker MB, Shoultz J, Codier EE (2007) Identifying emotional intelligence in professional nursing practice. Journal of Professional Nursing 23(1): 30-36.

Kotsou I, Mikolajczak M, Heeren A, Grégoire J, Leys C (2018) Improving emotional intelligence: a systematic review of existing work and future challenges. Emotion Review (Apr): 1-15.

Kourgiantakis T, Sewell K M, Hu R, Logan J, Bogo M (2019). Simulation in social work education: a scoping review. Research on Social Work Practice 30(4): 433-450.

Krug EG, Dahlberg LL, Mercy JA, Zwi AB, Lozano R (Eds.) (2002) World report on violence and health. World Health Organization. 
Kuula A (2006) Tutkimusetiikka; aineistojen hankinta, käyttö ja säilytys. (Research ethics; data acquisition, use and storage). Vastapaino.

Larew C, Sherrie Lessans S, Spunt D, Foster D, Covington BG (2006) Innovations in clinical simulation: application of Benner's theory in an interactive patients care simulation. Nursing Education Perspectives 27(1): 16-21.

Lowe DJ, Ireland AJ, Ross A, Ker J (2016) Exploring situational awareness in emergency medicine: developing a shared mental model to enhance training and assessment. Postgraduate Medical Journal 92(1093): 653-658.

Mikolajczak M (2009) Going beyond the ability-trait debate: the three level model of emotional intelligence. E-Journal of Applied Psychology 5(2): 25-31.

Nelis D, Kotsou I, Quoibach J, Hansenne M, Weytens F, Dupuis P et al. (2011) Increasing emotional competence improves psychological and physical well-Being, social relationships, and employability. Emotion 11(2): 354-366.

O'Meara P, Munro G, Williams B, Cooper S, Bogossian F, Ross L et al. (2014) Developing situation awareness amongst nursing and paramedicine students utilizing eye tracking technology and video debriefing techniques: a proof of concept paper. International Emergency Nursing 23(2): 94-99.

Paavilainen E, Flinck A (2013) National clinical nursing guideline for identifying and intervening in child maltreatment within the family in Finland. Child Abuse Review 22(3): 209-220.

Paavilainen E, Flinck A (2015) Lasten kaltoinkohtelun tunnistamisen tehokkaat menetelmät sosiaali- ja terveydenhuollossa. (Efficient methods for identifying child maltreatment in social and health care). Hoitotyön tutkimussäätiö.

Polit DF, Beck CT (2012) Nursing research: generating and assessing evidence for nursing practice. Wolters Kluwer Health/Lippincott \& Wilkins.

Puusa A, Juuti P (2020) Laadullisen tutkimuksen näkökulmat ja menetelmät. (Perspectives and methods in qualitative research). Gaudeamus $\mathrm{Oy}$.

Rantanen H, Paavilainen E (2018) Vanhemman voinnin arviointi ja perheen varhainen tukeminen lasten kaltoinkohtelun ehkäisytyössä. Perheen vointia kuvaavan lomakkeen (BCAP) käyttö lapsi- ja perhepalveluissa. (Parental assessment and early family support in prevention of child maltreatment. Use of the BCAP inventory in child and family services). Retrieved from: https://bit.ly/394PdQ6. [Accessed 23 July 2020]

Salminen-Tuomaala M (2019) Development of multiprofessional simulation-based education in South Ostrobothnia, Finland. Athens Journal of Health and Medical Sciences 6(3): 143-156.

Salminen-Tuomaala M (2020) Developing emotional intelligence and situational awareness through simulation coaching. Clinical Nursing Studies 8(2): 13-20.

Salminen-Tuomaala M, Hallila J, Niinimäki A, Paussu P (2020) The simulation coaching concept - A step towards expertise. Journal of Nursing Education and Practice 10(4): 83-90.

Salovey P, Brackett MA, Mayer JD (2004) Emotional intelligence: key readings on the Mayer and Salovey Model. National Professional Resources Inc. Dude Publishing.

Sedu Vocational Education (2020) Keitä Olemme? (Who are we?) Retrieved from: https:// www.sedu.fi/fi/Tietoa-Sedusta [Accessed 23 July 2020]

Seinäjoki University of Applied Sciences (2020) Seamk introduction. Retrieved from: https://www.seamk.fi/en/aboutus/seamk-introduction/. [Accessed 23 July 2020]

Stamer K (2017) Teaching strategies to increase emotional intelligence: do they make a difference in online RN-BSN students? SSRN. Retrieved from: https://ssrn.com/abs tract $=2995058$. [Accessed 23 July 2020] 
Stubbings L, Chaboyer W, McMurray A (2012) Nurses' use of situation awareness in decision-making: an integrative review. Journal of Advanced Nursing 68(7): 14431453.

Tanner CA (2006) Thinking like a nurse: a research-based model of clinical judgment in nursing. The Journal of Nursing Education 45(6): 204-211.

World Health Organization - WHO (2020) Child maltreatment. WHO.

Williams B, Reddy P, Marshall S, Beovich B, McKarney L (2017) Simulation and mental health outcomes: a scoping review. Advances in Simulation 2(2): 1-8. 
